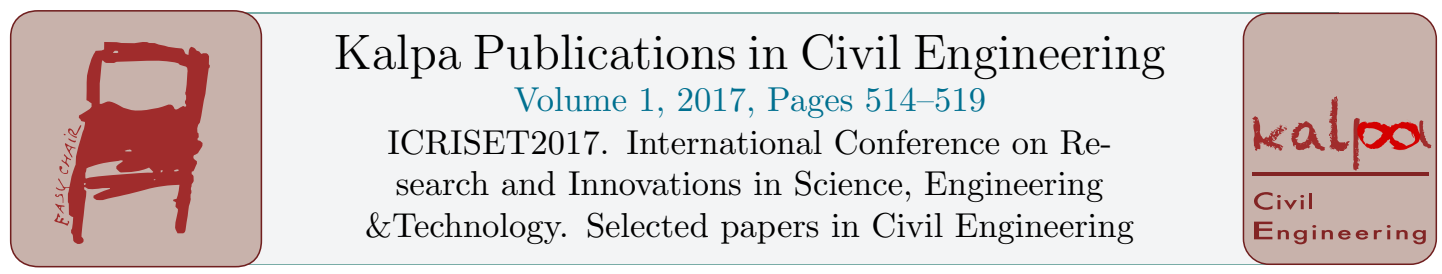

\title{
A Parametric Study on Behaviour of Geogrid Reinforced Earth Retaining Wall
}

\author{
Riddhi Vashi ${ }^{1}$, Amit Patel ${ }^{2}$, Krunali Patel ${ }^{3}$ \\ ${ }^{1,2,3}$ Assistant Professor \\ ${ }^{1,3}$ G.H.Patel College of Engineering and $\quad{ }^{2}$ B.V.Patel Institute of Technology, \\ Technology, Anand, Gujarat-388120, India Umrakh, Bardoli Gujarat-394345, India \\ riddhivashi@gcet.ac.in, amitbpatel05@gmail.com, \\ krunalipatelegcet.ac.in
}

\begin{abstract}
Reinforced soil retaining walls have become a conventional practice for economical retaining wall construction. For stability, geosynthetic reinforcement should have ample design strength, located at specific vertical spacing in the reinforced fill. Geosynthetic reinforcement design strengths and vertical spacing are easy to attain. If there are outcrops of heavily over consolidated soils, soft $r$ hard rocks in close vicinity to the retaining wall, the required reinforcement lengths into the reinforced fill may be difficult to achieve. In these circumstances, it becomes impossible to excavate the heavily over consolidated soil or rock. In that case, extent of reinforced fill has to be controlled to protect the wall face alignment which in turn results in short lengths of geosynthetic reinforcement.
\end{abstract}

Keywords-Geogrid, Reinforced, Plaxis-2D, FE method, Retaining Wall.

\section{Introduction}

The essential standards of earth reinforcement are set up in extraordinary amounts in nature by creatures and feathered creatures through the activity of tree roots. The bearing capacity of the soil is expanded by the reinforcement in this manner enhances the earth. It additionally diminishes the settlement of the structure. The development of fortified earth structure has turned out to be across the board in Geotechnical engineering hone in the most recent two decades as they are simple in development and practical when constructed with the typical strategies. Reinforcement of soil is proficient to enhance the mechanical properties of the soil. It is being strengthened by the expansion of basic component, for example, heaps; lime/concrete blended granular soil, metallic bars, manufactured sheet, lattices, and cells and so on. [2]

In civil engineering practices, the concept of combining two materials which have different strengths characteristics to form a composite material of greater strength is proverbial. Such 
examples of the composite materials are reinforced concrete constructions in which high tensile strength of steel is combined with the high compressive strength of concrete. In the same way, low tensile strength of soils can also be strengthened by using the materials of high tensile strength. This mobilisation of tensile strength is obtained by interaction of surface between the soil and the reinforcement through friction and adhesion. To obtain the required properties, the extensible materials such as metallic strips or polymeric reinforcement are placed within the soil.

Retaining walls should be intended to withstand sidelong earth pressures, water pressures, the impacts of surcharge loads and self-weight of the wall .It might be designed in unique cases like earthquake loads with the universal standards indicated in this area. Retaining walls should be intended for a life in light of thought of the conceivable long haul impacts of material disintegration on each of the material segments involving the wall. Lasting Retaining walls ought to be intended for a base life of 50 years and temporary retaining walls to be intended for a base life of 5 years. By its temperament, strengthened soil is a mix of basic and geotechnical designing. In geotechnical engineering, the use of incomplete variables to the different geotechnical parameters has not been found when all is said in done plan and general components of security are still utilized.

\section{Numerical Modelling in Plaxis 2D}

Modeling and analysis on Plaxis-2D software has resulted in considerable advances in the analysis and design for the reinforced soil walls in recent years. A large progress has been made in attempting to represent the behavior of reinforced soil walls in service and to investigate the mechanisms of soil structure interaction. For reinforced soil retaining walls, Simplified methods of analysis are available BS 006 (1995) [5]. All these traditional methods are based on simplified analysis or empirical rules, they cannot and do not provide the engineer with all the desired design information. They only provide very limited indications of soil movements and no information on the interaction with closest structures.

In a LE consideration one utilize the three equations of equilibrium and assume that strength is equally mobilized along some assumed potential shear surface. In FE method stresses in the soil will be distributed as a function of relative stiffness in different layers and regions in the soil. [1] Even for a moderate load some limited regions may reach yielding in shear, while other parts of soil may experience almost no shear. [6]

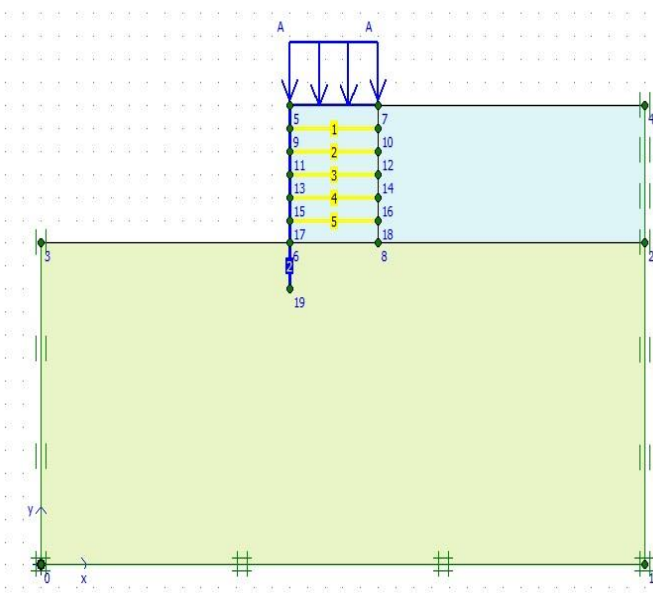

Figure 1: Plaxis 2D Model of Geogrid Reinforced Earth Retaining Wall.

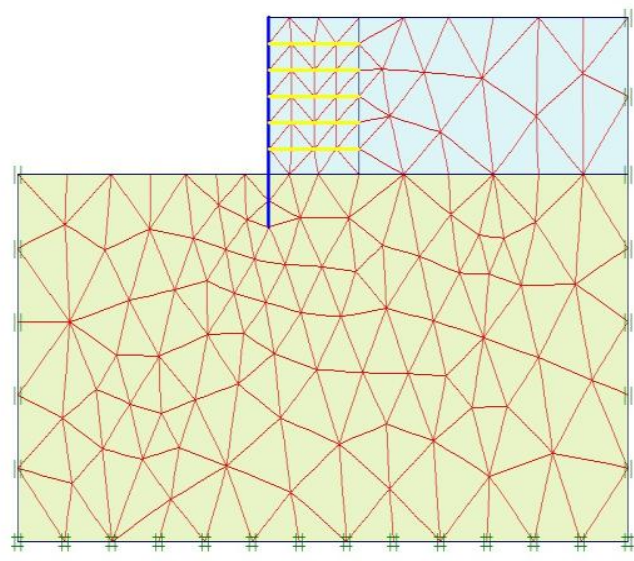

Figure 2: Mesh Generation of Geogrid Reinforced Earth Retaining Wall. 


\begin{tabular}{|c|c|c|c|c|}
\hline Parameter & Name & $\begin{array}{c}\text { Embankment } \\
\text { fill }\end{array}$ & $\begin{array}{c}\text { Foundation Soft } \\
\text { Clay }\end{array}$ & Unit \\
\hline & & General & & \\
\hline Material model & Model & Mohr-Coulomb & Mohr-Coulomb & - \\
\hline $\begin{array}{l}\text { Type of material } \\
\text { behaviour }\end{array}$ & Type & Drained & Undrained(A) & - \\
\hline $\begin{array}{l}\text { Soil unit weight above } \\
\text { phreatic level }\end{array}$ & $\gamma_{\text {unsat }}$ & 18 & 15 & $\mathrm{kN} / \mathrm{m}^{3}$ \\
\hline $\begin{array}{l}\text { Soil unit weight below } \\
\text { phreatic level }\end{array}$ & $\gamma_{\text {sat }}$ & 20 & 17 & $\mathrm{kN} / \mathrm{m}^{3}$ \\
\hline \multicolumn{5}{|c|}{ Parameters } \\
\hline Young's modulus & $\mathrm{E}$ & 30,000 & 2,000 & $\mathrm{kN} / \mathrm{m}^{2}$ \\
\hline Poisson's ratio & $v^{\prime}$ & 0.3 & 0.35 & - \\
\hline Cohesion & $c^{\prime}$ & 1 & 5 & $\mathrm{kN} / \mathrm{m}^{2}$ \\
\hline Friction Angle & $\varphi^{\prime}$ & 30 & 20 & 0 \\
\hline \multicolumn{5}{|c|}{ Flow Parameters } \\
\hline Data set & - & Standard & Standard & \\
\hline Soil type & - & Course & Course & \\
\hline $\begin{array}{l}\text { Horizontal permeability } \\
\text { (x,y-direction) }\end{array}$ & $\mathrm{k}_{\mathrm{x}}, \mathrm{k}_{\mathrm{y}}$ & 1.00 & $8.64 \times 10^{-5}$ & $\mathrm{~m} /$ day \\
\hline Vertical permeability & & $\begin{array}{r}1.00 \\
\text { Interfaces }\end{array}$ & $8.64 \times 10^{-5}$ & $\mathrm{~m} /$ day \\
\hline Interface strength & - & Rigid & Rigid & - \\
\hline Strength reduction factor & $\mathrm{R}_{\text {inter }}$ & 1.0 & 1.0 & - \\
\hline \multicolumn{5}{|c|}{ Initial } \\
\hline $\mathrm{K}_{\mathrm{o}}$ determination & - & Automatic & Automatic & - \\
\hline
\end{tabular}

Table 1: Material Parameters for Basic Reinforced Earth Models

For Geotextile data G1000 with EA $1000 \mathrm{kN} / \mathrm{m}$ is used in this paper.

\section{Results and Discussions}

\subsection{Impact of the Spacing of Geogrid}

Fig. 3 presents the Impact of the spacing of Geogrid on horizontal displacement of wall with respect to its height. It is shown that as the spacing of geogrid is increases the horizontal displacement of wall is also increases. It is shown from Fig. 4 that as increasing the spacing of geogrid maximum forces in the geogrid is also increases. Figure also indicates that at the top most layer of geogrid the maximum force is higher as compared to the other layer. 


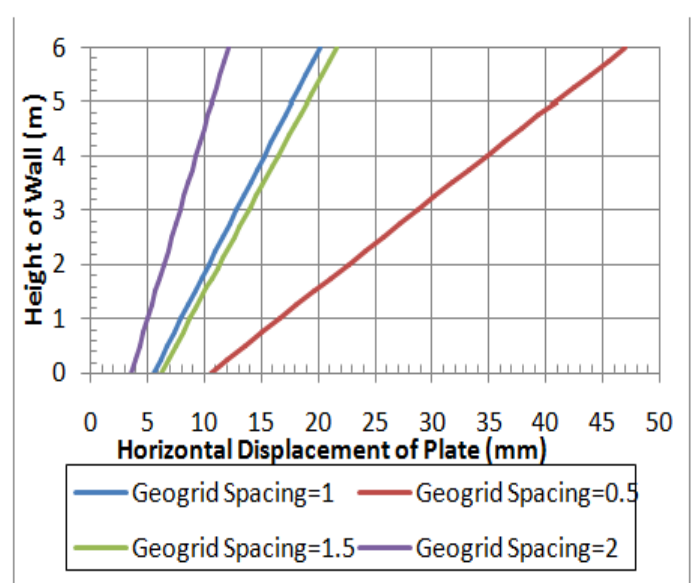

Figure 3: Impact of Spacing of Geogrid on Horizontal Displacement of Plate.

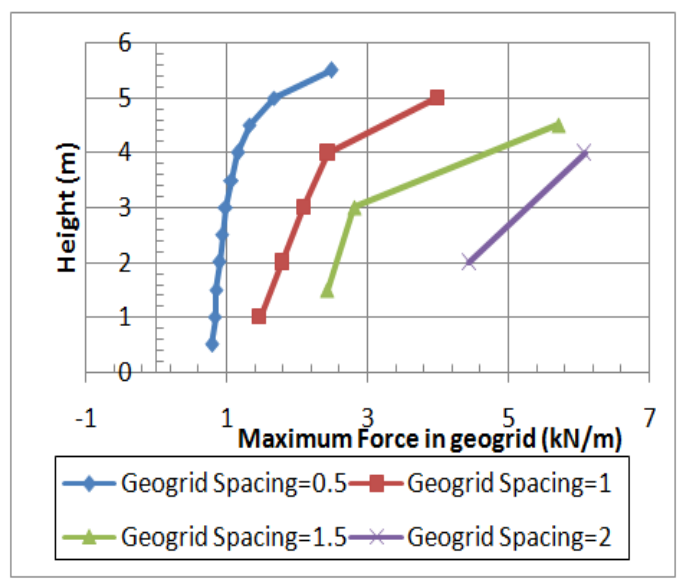

Figure 4: Impact of Spacing of Geogrid on Maximum Tensile Force in Geogrid.

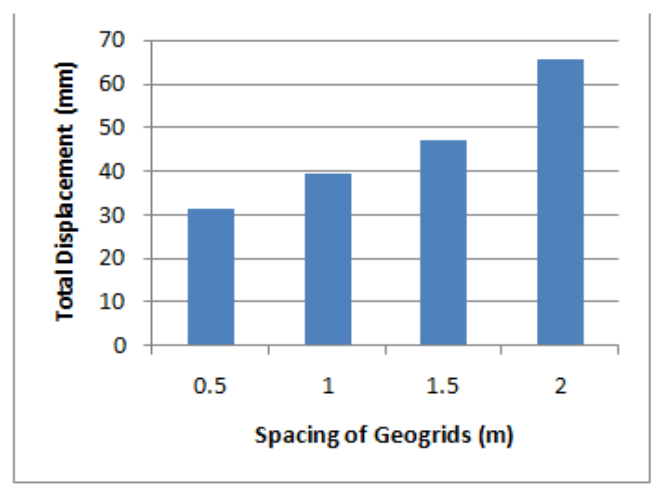

Figure 5: Impact of Spacing of Geogrid on Vertical Displacement.

Fig. 5 shows the Impact of spacing of geogrid on vertical displacement. [3] It shows that as we increase the spacing of geogrid the vertical displacement is also increases.

\subsection{Impact of the Height of Wall}

Fig. 6 presents the Impact of the height of wall on horizontal displacement of wall. The height of the wall is increases the horizontal displacement of wall is also increases. It is shown from Fig. 7 that as we increase the height of the wall the maximum forces in the geogrid is also increases. Figure also indicates that at the top most layer of geogrid the maximum force is higher as compared to the other layer. 
A Parametric Study on Behaviour ...

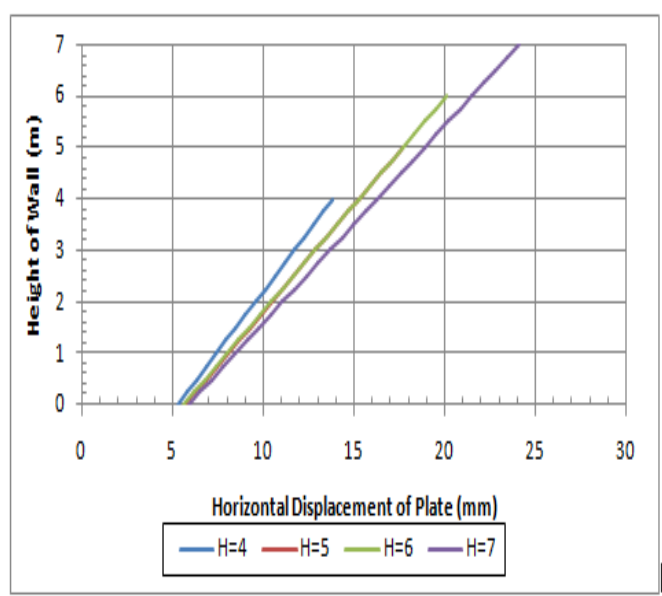

Figure 6: Impact of Height of The Wall on Horizontal Displacement of Plate.



Figure 8: Impact of Height of The Wall on Total Displacement.
Riddhi Vashi, Amit Patel and Krunali Patel

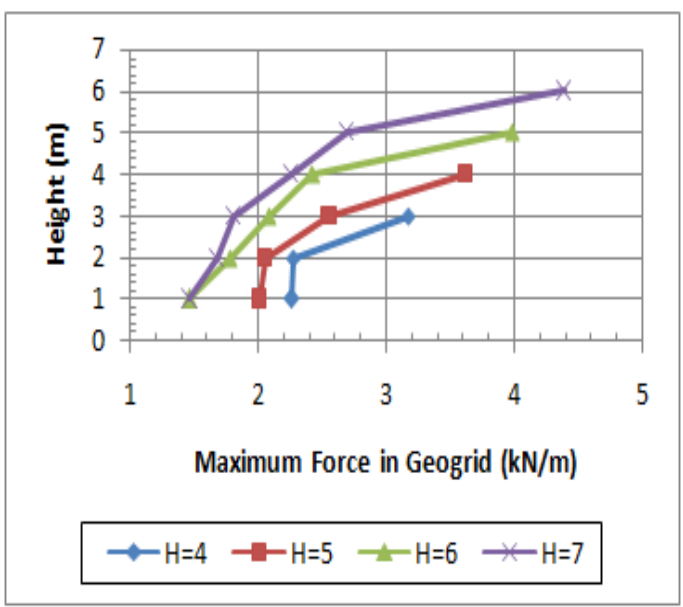

Figure 7: Impact of Height of The Wall on Maximum Tensile Force in Geogrid.

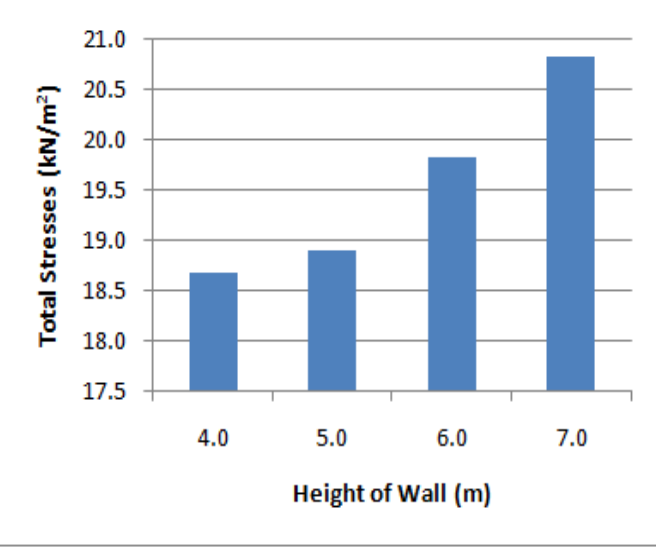

Figure 9: Impact of Height of The Wall on Total Stresses.

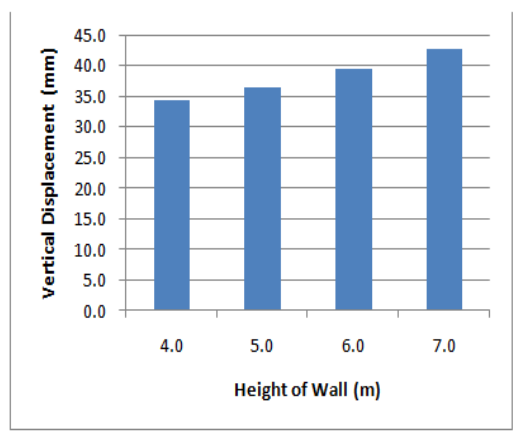

Figure10: Impact of Height of The Wall on Vertical Displacement. 
Fig. 8 represents the Impact of height of the wall on total displacement. It shows that as we increase the height of the wall the total displacement is also increases. Fig. 9 represents the Impact of height of the wall on total stresses. It shows that as we increase the height of the wall the total stresses is also increases. Fig. 10 shows that as the height of the wall increases, the vertical displacement is also increases.

\section{Conclusion}

From the parametric study of spacing of geogrid and height of wall following Conclusions can be drawn as, spacing of geogrid plays a major role to reduce the total settlement and total stresses. If the spacing of geogrid is increasing from $1 \mathrm{~m}$ to $1.5 \mathrm{~m}$ the total displacement is increased by $10 \%$ and if spacing is reduced up to $0.5 \mathrm{~m}$ the total displacement is reduced by $24.31 \%$. It states that by reducing the spacing of intermediate geogrid layer there should be a reduction of settlement and stresses. Although it should be noted that there will be an effective use of spacing to enhancing the economy also.

The optimum length of geogrid plays a major role in the RE Wall. If the length of geogrid is reduced from $5 \mathrm{~m}$ to $3.5 \mathrm{~m}$, there is an increase in total displacement of $84 \%$ and if the length is increased by $4.5 \mathrm{~m}$ the total displacement is increase by $9 \%$ as compared to $5 \mathrm{~m}$ length of geogrid. The height of the RE Wall increasing from $5 \mathrm{~m}$ to $7 \mathrm{~m}$, there is a $7 \%$ increase in total displacement but after some extent if the height is increasing there will a major difference in the settlement.

\section{References}

A.L.Shinde, J.N.Mandal, (2007), “ Behaviour of reinforced soil retaining wall with limited fill zone" Geotech Geol Eng (2007)

D.V.Reddy et al, (2003) "long term behaviour of geosynthetic reinforced mechanically stabilized earth (MSE) wall system " JOURNAL OF ENGINEERING MECHANICS

Faisal Ali et al, (2011) “Finite element analysis of a vertical reinforced earth wall'International Journal of the Physical Sciences Vol. 6(28)

Firas A. Salman, Mohammed Y. Fattah, Dunya K. Sabre, (2011) "Long term behaviour of a retaining wall resting on clayey soil" International Journal of the Physical Sciences Vol. 6(4), pp. 730745

Hadi Abioghli, (2011) "Effect of Changes of Mesh Size on the Numerical Analysis of Reinforced Soil Walls" Australian Journal of Basic and Applied Sciences.

Hadi Abioghli, (2011) "Parametric study of reinforced soil walls with the finite element method" Australian Journal of Basic and Applied Sciences

K.G. Garg. (1998), "Retaining wall with reinforced backfill a case study" Geotextiles and Geomembranes 16 (1998) 135-149,6th International Advanced Technologies Symposium (IATS'11), 16-18 May 2011, Elazı̆ğ, Turkey

Mohammed Y. Fattah , Dr. Mustafa A. Yousif, (2009) "Finite element analysis of reinforced earth walls" Journal of Engineering and Development, Vol. 13, No. 3, September (2009)

Suksun Horpibulsuk et al, (2011) "Performance of an earth wall stabilized with bearing reinforcements" Geotextiles and Geomembranes 29 (2011) 514-524. 